\title{
Syndrome of transient headache and neurological deficits with cerebrospinal fluid lymphocytosis (HaNDL)
}

\section{Case report}

The syndrome of transient headache and neurological deficits with cerebrospinal fluid lymphocytosis (HaNDL) is a rare benign form of secondary headache. This syndrome was first described by Bartleson JD et al. ${ }^{1}$ and the term HaNDL was proposed in 1995 by Berg MJ et al. ${ }^{2}$ Approximately 100 cases of HaNDL syndrome have been described in the literature, but it is assumed that the prevalence of this type of headache is higher, approximately 0.2 case per 100,000 population. ${ }^{3-6}$ Most cases have been reported by Gómez-Aranda et al. ${ }^{7}$ who described 50 patients with HaNDL syndrome. ${ }^{7}$ Below we present our own case report of a female patient with HaNDL syndrome.

Patient E, 21 years old, with no history of neurological disease, suddenly experienced numbness in the left foot, which was successively followed by numbness in the left arm, left side of the face and tongue, and slurred speech; these symptoms resolved spontaneously. Each of the symptoms lasted approximately 10 minutes. Nausea developed 15 minutes later, and after another 15 minutes the patient experienced an intense pulsating headache in the right temporal region scoring 8 on the Visual Analogue Scale (VAS) and accompanied by vomiting, photo-, phono-, and osmophobia. The pain persisted for 6-8 hours, and afterwards the patient fell asleep. The patient experienced three more similar episodes with an interval of 2 to 3 days. Two days after the last episode, the patient again woke up with an intense headache, feeling discomfort in an arm and the face. The headache score reached 10 on the VAS. Due to these complaints, the patient was admitted to a hospital.

On admission: no abnormalities in the general clinical or neurological status. Body temperature on admission: $37.0^{\circ} \mathrm{C}$. A complete blood count revealed a moderate leukocytosis-13.3 $109 / \mathrm{L}$ (reference interval: 4.0-9.0•109/L), but a follow-up test performed the next day was normal (white blood cell count: 6.8·109/L). Serological tests for HIV infection, hepatitis B and C, as well as syphilis, were negative. A cerebrospinal fluid examination revealed a lymphocytic pleocytosis $\left(86 \mathrm{cells} / \mathrm{mm}^{3}\right)$ and an insignificant increase in protein content (to $66 \mathrm{mg} / \mathrm{dL}$ ), in the absence of other abnormalities.

Within 6 days after the lumbar puncture, the patient started experiencing headache episodes of a different type, which developed a few minutes after a body position change from supine to upright and worsened, while the patient was in the upright position, from moderate to intense, being diffuse and accompanied by tinnitus, hypoacusis, and nausea. In the horizontal position, the headache significantly improved or disappeared completely. This headache completely resolved within 5 or 6 days. This type of pain was considered to be a post-puncture headache.

Electroencephalography (EEG) revealed no abnormalities Brain MRI: no signs of focal lesions in the brain matter were observed. Chest X-ray imaging: no abnormalities. Duplex ultrasound scanning of the extracranial portions of the brachiocephalic vessels: no abnormalities. ECG:sinus arrhythmia, heart rate: 76 beats per minute.
Volume 8 Issue 3 - 2018

\author{
Gyuzyal Tabeeva, ${ }^{1,2}$ Julia Azimova, ${ }^{2}$ Kirill \\ Skorobogatych, ${ }^{2}$ Aleksey Sergeev, ${ }^{1,2}$ Eugene \\ $\mathrm{Klimov}^{3}$ \\ 'Department of neurology and neurosurgery, IM Sechenov \\ medical university, Russia \\ ${ }^{2}$ University Headache Clinic, Russia \\ ${ }^{3}$ Department of Genetics, Faculty of Biology, Lomonosov \\ Moscow State University, Moscow, Russia
}

Correspondence: Gyuzyal Tabeeva, Department of neurology and neurosurgery, IM Sechenov medical university, Russia, Email grtabeeva@gmail.com

Received: February 28, 2018| Published: May 07, 2018

Abdominal ultrasonography: normal. Ophthalmologist's consultation: no abnormalities detected. Infectious disease specialist's consultation: serous meningitis with migraine-like headache. Serological tests were performed for the Epstein-Barr virus, cytomegalovirus, herpes simplex virus type 2, Borrelia and Mycoplasma, tuberculosis - all results were negative. The headache resolved during the hospital stay. After discharge from the hospital, the patient experienced no such headache attacks and no other symptoms during 10-month follow-up. No abnormalities were observed in the general clinical or neurological status.

\section{Discussion}

The recurrent episodes of acute headache with accompanying symptoms indicative of neurological deficits perfectly meet the criteria of the syndrome of transient headache and neurological deficits with cerebrospinal fluid lymphocytosis (HaNDL). ${ }^{8}$ The patient experienced these episodes for the first time, and they did not recur afterwards (during the 10-month follow-up period). Besides, the patient had an episode of cephalalgia after a lumbar puncture. This episode occurred in the orthostatic position, so it can be viewed as a post-puncture headache.

When HaNDL syndrome is suspected, a number of conditions that may have a similar clinical presentation should be ruled out. ${ }^{3,9}$ These conditions include:

i. migraine (including basilar artery and sporadic hemiplegic migraines);

ii. transient migraine coma syndrome with focal cerebral edema, pleocytosis in the cerebrospinal fluid, and cerebellar ataxia, causing episodes of headache and coma in combination with progressive ataxia over a period of many years;

iii. reversible cerebral vasoconstriction syndrome (Call-Fleming syndrome) characterized by sudden-onset thunderclap headache 
and transient focal neurological symptoms. The underlying mechanism of this syndrome is a reversible segmental or multifocal cerebral artery vasoconstriction of various origins: idiopathic, associated with the use of vasoactive substances (medicinal products, alcohol, narcotic drugs), angiitis-associated;

iv. viral meningitis (especially meningitis caused by the Epstein-Barr virus, cytomegalovirus, herpes simplex virus, or HIV);

v. meningitis associated with cat scratch disease;

vi. benign recurrent Mollaret's serous meningitis;

vii. bacterial serous meningitis (neuroborreliosis, neurosyphilis, neurobrucellosis, tuberculosis, Mycoplasma infection);

viii. paraneoplastic meningitis;

ix. auto immune diseases with neurological manifestations (Behçet's disease, systemic lupus erythematosus).

In addition, transient neurological symptoms require differential diagnosis with transient ischemic attack (TIA) and epileptic seizure. The key clinical differences that allow differentiation of neurological disorders in patients with HaNDL syndrome from those of a TIA are gradual onset of neurological symptoms and successive development of various symptoms over some tens of minutes. The neuro imaging methods (CT, MRI) reveal no changes, with the exception of rare cases of small hyperintense foci on T2-weighted MRI sequences in the basal ganglia region.

The lymphocytic pleocytosis necessitated differential diagnosis with CNS infections, in particular viral meningitis. In the reported case the patient had no clinical signs of meningeal syndrome and no general inflammatory reactions, such as high fever, leukocytosis, or elevated ESR. To rule out infections, the patient underwent serological tests for herpes simplex, herpes zoster, cytomegalovirus, the Epstein-Barr virus, HIV, tuberculosis, and syphilis, all these tests were negative. As mentioned above, the clinical presentation of HaNDL syndrome is very similar to that of migraine with aura. The clinical symptoms distinguishing between these two diseases are presented in Table 1.

Table I Differential diagnosis between the syndrome of transient headache and neurological deficits with cerebrospinal fluid lymphocytosis (HaNDL) and migraine with aura

\begin{tabular}{|c|c|c|}
\hline Symptom & HaNDL syndrome & Migraine with aura \\
\hline \multicolumn{3}{|l|}{ Course of disease } \\
\hline onset & $-30-40$ years & - before 20 years \\
\hline \multirow[t]{3}{*}{ frequency of attacks } & $\begin{array}{l}\text { - frequent attacks at an interval of several } \\
\text { days from the onset of disease }\end{array}$ & - relatively rare, once a month or less frequently \\
\hline & - no relapse occurs after a series of attacks & \\
\hline & & - lifelong \\
\hline \multicolumn{3}{|l|}{ prognosis } \\
\hline \multicolumn{3}{|c|}{ Types of aura symptoms } \\
\hline \multicolumn{3}{|l|}{ visual } \\
\hline sensory & $-18 \%$ & $-99 \%$ \\
\hline speech & $-70 \%$ & $-31 \%$ \\
\hline \multirow[t]{2}{*}{ motor } & $-60 \%$ & $-18 \%$ \\
\hline & $-42 \%$ & $-6 \%$ \\
\hline Visual disturbances & Loss of visual fields & $\begin{array}{l}\text { Zig-zag shimmering line spreading from the centre of the visual field } \\
\text { to its periphery and replaced with a scotoma, photopsias }\end{array}$ \\
\hline Aura duration & hours to days, 5 hours on the average & less than one hour \\
\hline Headache & $69 \%$ - bilateral & hemicrania prevails \\
\hline $\begin{array}{l}\text { Concomitant } \\
\text { symptoms }\end{array}$ & $\begin{array}{l}\text { nausea, vomiting, photo- and phonophobia, } \\
\text { fever }\end{array}$ & nausea, vomiting, photo- and phonophobia, fever - very rare \\
\hline
\end{tabular}

\section{Acknowledgements}

None.

\section{Conflict of interest}

The author declares no conflict of interest.

\section{References}

1. Swanson JW, Bartleson JD, Whisnant JP. A migrainous syndrome with CSF pleocytosis. Neurology. 1981;31(10):1257-1262.

2. Berg MJ, Williams LS. The transient syndrome of headache with neurologic deficits and CSF lymphocytosis. Neurology. 1995;45(9): $1648-1654$.

3. Mitsikostas DD, Pascual J. Pseudomigraine with pleocytosis. In: J Olesen, et al. (Eds.), The headaches. $3^{\text {rd }}$ ed. Lippincott Williams \& Wilkins; 2006. p. $945-947$.

4. Quintas S, López Ruiz R, Trillo S, et al. Clinical, imaging and electroencephalographic characterization of three cases of HaNDL syndrome. Cephalalgia. 2017:333102417735846.

5. Babi MA, Applebee A, Shapiro R, et al. Syndrome of transient headache and neurologic deficits with cerebrospinal fluid lymphocytosis presenting as acute neurological emergencies. Cephalalgia. 2017;37(3):284-289. 
6. Barón J, Mulero P, Pedraza MI, et al. Síndrome HaNDL: correlación entre la topografía del déficit neurológico y las alteraciones en electroencefalograma y SPECT en una serie de 5 nuevos casos. Neurología. 2016;31(5):305-310.

7. Gomez-Aranda F, Canadillas F, Marti-Masso JF, et al. Pseudomigraine with temporary neurological symptoms and lymphocytic pleocytosis. A report of 50 cases. Brain. 1997;120( Pt 7):1105-1113.
8. Headache classification committee of the international headache society (IHS). The international classification of headache Disorders, 3rd ed (beta version). Cephalalgia. 2013;33(9):629-808.

9. Ducros A, Boukobza M, Porcher R, et al. The clinical and radiological spectrum of reversible cerebral vasoconstriction syndrome. A prospective series of 67 patients. Brain. 2007;130(Pt 12):3091-3101. 